\title{
Text Neck Syndrome: The Pain of Modern Era
}

\author{
Supriya Kumari', Ravi Kumar², Divyam Sharma² \\ ${ }^{1}$ Student, Department of Physiotherapy, G.D Goenka University, Sohna, Haryana -122103 \\ ${ }^{2}$ Student, Department of Physiotherapy, Galgotias University, Uttar Pradesh, India - 203201
}

Corresponding Author: Ravi Kumar

\begin{abstract}
Introduction- The text neck syndrome is a repetitive stress injury induced by prolonged neck flexion at different angles and pain sustained from excessive watching or texting on handheld devices for long periods. It should be referred to as "Modern Era Pain" due to its direct association with the modern era's Gadgets.

Aim - This study aimed to determine the prevalence of text neck syndrome and neck pain among college students and to find the effect of neck pain on their active daily lives.

Methodology - A personalized questionnaire was designed in the Google Forms and distributed among the around college students by using Snowball sampling techniques. The questionnaire contained four parts: consent letter, sociodemographic details, NDI questionnaire, and fourth part of questionnaire contained vas scale and personalized question about how neck pain impact their active daily life.

Result - Out of 283 responses, 36.5 percent of respondents reported mild text neck syndrome, 23.4 percent reported moderate, 2.1 percent reported severe and complete text neck syndrome, and 35.7 percent did not suffer text neck syndrome. And $73.4 \%$ people reported mild to severe pain in neck and upper back region.
\end{abstract}

Conclusion- Prevalence of text neck syndrome is found greater in study as compared to the findings of other previous studies.

Key Words- Neck pain, Pain of modern era, NDI, Upper back pain, Musculoskeletal disorder

\section{INTRODUCTION}

Nowadays, the mobile phone is the most popular and widely used device for various daily activities such as exchanging information, accessing the internet, watching movies, using social media sites, gaming, and a variety of other activities. A survey had shown that $79 \%$ of the $18-44$ year-old people spend most of their time with smartphones.[1]

According to a recent study conducted on 2061 students, 74.8 percent of respondents were addicted to mobile phone and moderate to severe nomophobic [2]. Those who were constantly engaged to their phones may suffer from worry, stress, panic disorders, and various other psychological illnesses. Apart from these psychological disorders, individuals may suffer from many physical disorder and text neck syndrome is one of the major problems among them.

The term "TEXT NECK”' was first coined by an US chiropractor Dr. Dean L. Fishman.[4] This term is used to describe neck discomfort and injury of upper back muscle which is caused by the frequent flexion of neck at various angles, while staring down at a mobile phone which alters the normal curve of the cervical spine.

The text neck syndrome should be considered as "Pain of the Modern Era" since it is caused by modern-era gadgets such as cell phones, computers, and other smart devices, and it causes acute to chronic pain in the neck and upper back area. 
A report shows that when the head is flexed 15 degrees,[5] the forces acting on the neck are 27 pounds, 40 pounds when the neck is flexed 30 degrees, 49 pounds when the neck is flexed 45 degrees, and 60 pounds when the neck is flexed 60 degrees; the model prediction at 90 degrees is not accurate.

There had been a number of researches conducted to determine the effects of smartphone addiction on the musculoskeletal system.[6] and several researchers reported a strong connection between neck and shoulder pain and total time spent using a mobile phone.

Specifically, this research was aimed to determine the prevalence of text neck syndrome among Indian college students, as well as to determine how text neck syndrome impacts them in their daily life on a regular basis.

\section{METHODOLOGY}

\section{Study design And Data collection}

This descriptive cross-sectional survey was conducted on Indian students. A customized e-questionnaire was developed in Google Form and sent to those college students who use their phones for more than 3 hours per day, using various social media platforms. The questionnaire was divided into four sections: the first section contained a consent form, which participants must sign before proceeding to the second section of the questionnaire; the second section of the questionnaire included socio demographic questions; the third section of the questionnaire was made of general questions about pain, pain intensity, and pain management; and the fourth section of the questionnaire consisted the Neck disability index (NDI).

\section{Inclusion criteria}

- Participants were Indian.

- Participants were students from different universities/institutions

- Smartphones must be used for at least $\geq 3$ hours each day.
- There was no previous history of an accident or severe injury.

- There was no recognized disease that may cause pain in the neck or upper limb, and there is no any neurological or cardiovascular problem.

\section{ETHICAL ISSUES}

This research was performed by following all of the principles of the Helsinki Declaration [7]. The participants' participation in this research was voluntary by filling out a consent form with the word "yes" in the first section of the questionnaire.

Participants' data were kept confidential and accessible only to the authors and research guide.

\section{TOOL}

\section{Neck disability index}

The third part of the survey form includes an NDI questionnaire [8]. The NDI questionnaire was created to gather information on how neck pain affected one's ability to function in everyday life. There were ten questions in this section, each of which had six options with a score ranging from 0 to 5 . Score is found by using a given formula.

\section{Score: Total score / total possible score Transform to percentage score $\times 100=$ \%points}

The results of the tests can be evaluated as a raw score, with a maximum score of 50, or as a percentage of a maximum possible score. The Higher score implies that the patient has reported greater neck disability.

\section{STATISTICAL ANALYSIS}

The statistical analysis was performed using the SPSS program.[9] Descriptive analysis was conducted as a frequency analysis for sociodemographic variables such as age, gender, time spent on the phone, and NDI questionnaire was analysed by the provided frequency. and a paired t test was conducted in between NDI result and the participant's age group to 
determine which age group is more adversely affected by neck disability.

\section{RESULT}

There were 283 participants in this research, which was drawn from a total sample of 335 college students. 52 students were excluded from the overall sample because their sociodemographic characteristics did not meet the inclusion criteria of this study. Out of a total of 282 participants, 108 were male, and the remaining 174 were female.

Out of total, $73.4 \%$ (207) students were from age group 18-24, 16\% (45) student were from age group 25-34, 8.5\% (24) student were below 18, and 2.1\% (6) students were from age group 35 - 40. Table 1 shows participants sociodemographic data and their mobile phone usage. In all, 39.4 percent of students reported spending up to 7 hours per day on mobile and other smart devices, while 27.7 percent reported spending $3-4$ hours per day on their phones. The survey found that $18.1 \%$ of students checked their phones for fewer than three hours, while $10.6 \%$ of respondents used their cell phones for 8 - 10 hours each day. And $4.3 \%$ of students used their smartphones more than 10 hours per day.

According to total responses, 58.5 percent of individuals experienced discomfort in their neck, upper back, or shoulder in the preceding three months and sought medical therapy to alleviate pain.
41.5 percent of the respondent had doesn't experience any discomfort in the previous three months.

Graph 1 illustrates the intensity of pain among students who have had pain in the past three months and received minor medical treatment due to the pain and the severity of pain. 36.2 percent of students reported moderate pain, 27.7 percent reported mild pain, 9.6 percent reported severe pain, 2.1 percent reported extremely severe pain, and 1.1 percent reported the worst pain they had ever experienced.

The neck disability index score is shown in Table 2. 36.4 percent of respondents reported having a mild disability, $36.0 \%$ reported having no impairment, 23.4 percent reported having a moderate disability, and 2.1 percent reported having a severe, and rest 2.1 percent reported permanent disability.

\begin{tabular}{|l|l|l|}
\hline \multicolumn{3}{|c|}{ Table 1- Socio-demographic variables } \\
\hline Variables & Frequency & Percentage \\
\hline Male & 108 & 38.3 \\
Female & 174 & 61.7 \\
\hline Age & 24 & 8.5 \\
\hline Under 18 & 207 & 73.4 \\
$18-24$ & 45 & 16 \\
$25-34$ & 6 & 2.1 \\
35-40 & 51 & 18.1 \\
Time Spent on mobile phone & 27.7 \\
\hline Less than 3 hours & 78 & 39.4 \\
3 - 4 hours & 111 & 10.6 \\
5 - 7 hours & 30 & 4.2 \\
8 - 10 hours & 12 & 58.5 \\
Above 10 hours & 165 & 41.5 \\
\hline Experienced pain in last 3 month & 117 \\
\hline Yes &
\end{tabular}

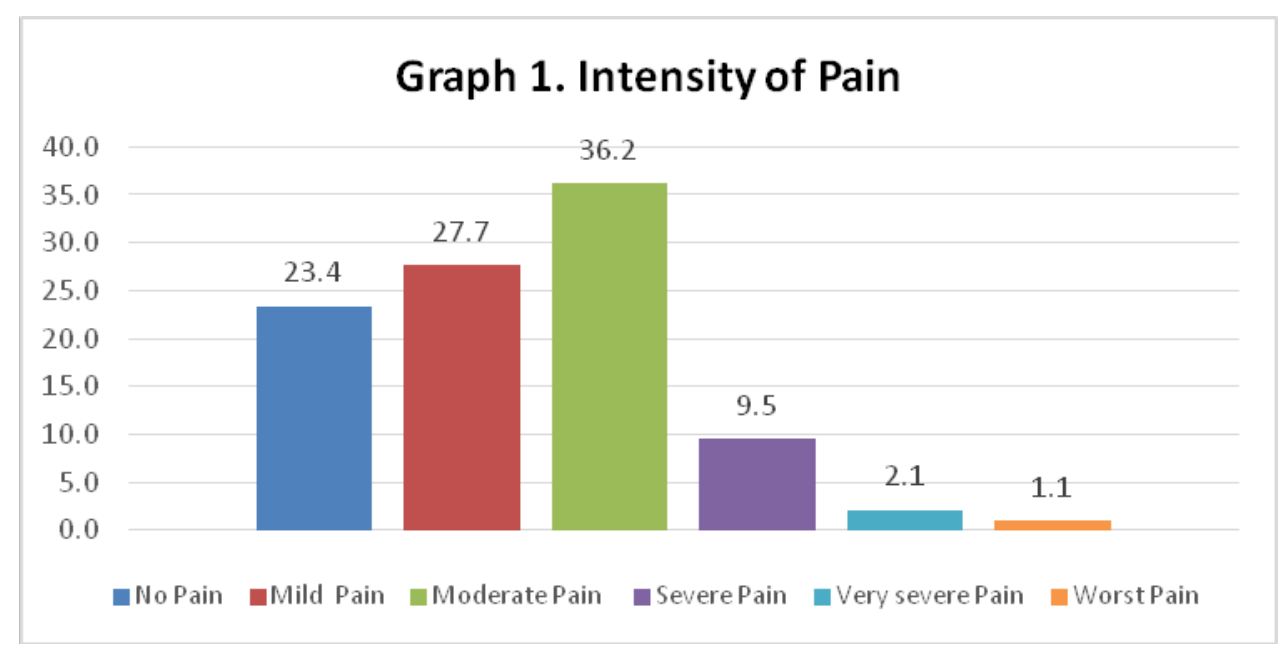




\begin{tabular}{|c|c|c|}
\hline \multirow[t]{2}{*}{ Variable } & \multicolumn{2}{|c|}{ Gender of Respondent } \\
\hline & Male $(n=108)$ & Female (174) \\
\hline \multicolumn{3}{|l|}{ Neck disability index } \\
\hline Complete disability & 48 & 53 \\
\hline Mild disability & 39 & 64 \\
\hline Moderate disability & 18 & 48 \\
\hline No disability & 3 & 3 \\
\hline Severe disability & 0 & 6 \\
\hline
\end{tabular}

\section{DISCUSSION}

Now-a-days, a person's life is incomplete without mobile phones. They need smartphones for a variety of everyday tasks such as educational purposes, gaming, listening to music, and a number of other activities. In some people, smartphone addiction had risen to such a level that people were spending much more of their time on them. The smartphone addiction is referred to as Nomophobia.

According to a recent study conducted on 2061 students, (Kumar, et al.: Nomophobia) shows 74.8 percent of respondents were moderately nomophobic, and 18.9 percent of respondents were severely nomophobic. In this study, the researchers reported that males were more nomophobic than females.

Aside from psychological effects, excessive usage of the smartphone also had a lot of negative effect on our physical health. Several studies had shown harmful effect of smartphone to our physical health.[12][13][14]

In this research, we discovered that 36.5 percent of respondents had continuous neck stress and had a mild level of neck disability, while $23.4 \%$ had moderate neck disability, $2.1 \%$ percent had severe and complete neck disability, and the remaining 35.8 had no neck disability. Female respondents were found to be more affected by neck disability than male respondents. In total, 61.7 percent of respondents were female, while 38.3 percent were male.

The result of our study was little bit similar to the findings of (Lee et al.) [14] using the neck disability index, they conducted a correlation study with text neck syndrome and discovered that 62.92 percent of those who answered the survey had no disability,
32.85 percent had mild disability, 3.04 percent had moderate disability, and the remaining 1.19 percent were severely affected by neck disability. Additionally, the research discovered similar to many other studies. According to research conducted by (Samani et al.) [15] in 2018, 35 percent of smartphone users suffered from text neck syndrome. In another research, (Alzaid et al.) in 2018 discovered that the age range of 15-18 was the most susceptible to developing neck discomfort among the general population. In research on physiotherapy students Ahmed et al. found that $54 \%$ of respondents were nomophobic and experienced musculoskeletal discomfort in the upper back area.

\section{CONCLUSION}

The text neck syndrome should be considered as "Pain of the Modern Era" since it is caused by modern-era gadgets such as cell phones, computers, and other smart devices.

The findings of this research reveals that the neck disability of respondents is greater in this study when compared to the findings of other previous studies. This study also revels the prevalence of text neck syndrome is rising day by day in comparison to previous studies.

Acknowledgement: None

\section{Conflict of Interest: None}

\section{Source of Funding: None}

\section{Ethical Approval: Approved}

\section{REFERENCES}

1. Neupane, S., Ali, U. T. I., Mathew, A., \& College, M. V. S. (2017). Text Neck Syndrome - Systematic Review. Imperial Journal of Interdisciplinary Research, 7, 141-148.

2. Kumar R, Kumari S, Bharti P, Sharma D. Nomophobia: A rising concern among Indian students. Ind Psychiatry J 2021

3. Khan, A. F., Gillani, S. F. U. H. S., Khan, A. F., \& Wahid, A. (2018). Are you 
suffering pain neck due to smart phone text neck syndrome. Pakistan Journal of Medical and Health Sciences, 12(3), 1095-1097.

4. Hansraj, K. K. (2014). Assessment of stresses in the cervical spine caused by posture and position of the head. Surgical Technology International, 25, 277-279. http://www.ncbi.nlm.nih.gov/pubmed/25393 825

5. AlAbdulwahab, S. S., Kachanathu, S. J., \& AlMotairi, M. S. (2017). Smartphone use addiction can cause neck disability. Musculoskeletal Care, 15(1), 10-12. https://doi.org/10.1002/msc.1170

6. Kumar, R., Sharma, D., Khan, S., Singh, S., \& Pandey, R. (2021). Prevalence of WorkRelated Stress and Addiction Due To It among Indians. World Journal of Research and Review, 13(2), 9-12. https://doi.org/10.31871/wjrr.13.2.5

7. Vernon, H., \& Mior, S. (1991). The neck disability index: A study of reliability and validity. Journal of Manipulative and Physiological Therapeutics, 14(7), 409-415. https://pubmed.ncbi.nlm.nih.gov/1834753/

8. Kumar, R., Kumari, S., Sharma, D., Bharti, P., \& Bhawna, K. (2020). Survey-Based Study on Anxiety Disorder among Indians Due to the COVID-19 Global Pandemic. Ijcrt, 8(10), 979-987.

9. Kumar, R., Kumari, S., Bharti, P., \& Sharma, D. Nomophobia: A rising concern among Indian students. Ind Psychiatry J. https://doi.org/10.4103/ipj.ipj_134_21

10. Grimby-ekman, A., Hagberg, M., Gustafsson, E., \& Thom, S. (2017). Texting on mobile phones and musculoskeletal disorders in young adults: A fi ve-year cohort study. Applied Ergonomics, 58, 208214.

https://doi.org/10.1016/j.apergo.2016.06.01 2

11. Ahmed, S., Akter, R., Pokhrel, N., \& Samuel, A. J. (2021). Prevalence of text neck syndrome and SMS thumb among smartphone users in college-going students: a cross-sectional survey study. Journal of
Public Health (Germany), 29(2), 411-416. https://doi.org/10.1007/s10389-019-01139-4

12. Hansraj, K. K. (2014). Assessment of stresses in the cervical spine caused by posture and position of the head. Surgical Technology International, 25, 277-279. http://www.ncbi.nlm.nih.gov/pubmed/25393 825

13. Lee, J. I., \& Song, H. S. (2014). The Correlation Analysis between Hours of Smartphone Use And Neck Pain in the Gachon University Students. The Acupuncture, 31(2), 99-109. https://doi.org/10.13045/ACUPUNCT.2014 028

14. Samani, P. P., Athavale, N. A., Shyam, A., \& Sancheti, P. K. (2018). Awareness of text neck syndrome in young-adult population. International Journal Of Community Medicine And Public Health, 5(8), 3335$3339 . \quad$ https://doi.org/10.18203/23946040.IJCMPH20183057

15. Alzaid, A. N., Alshadoukhi, O., Alnasian, A., Al Tuwairqi, M., Alotaibi, T. M., \& Aldossary, F. H. (2018). The Prevalence of Neck Pain and the Relationship between Prolonged Use of Electronic Devices and Neck Pain in a Saudi Arabia: Cross Sectional Study in Saudi Arabia. The Egyptian Journal of Hospital Medicine, 31(5691), 1-8. https://doi.org/10.12816/0044856

16. Ahmed, Pokhrel, N., Roy, S., \& Samuel, A. J. (2019). Impact of nomophobia: A nondrug addiction among students of physiotherapy course using an online crosssectional survey. Indian Journal of Psychiatry, 77. https://doi.org/10.4103/PSYCHIATRY.IND IANJPSYCHIATRY_361_18

How to cite this article: Kumari S, Kumar R, Sharma D. Text neck syndrome: the pain of modern era. Int J Health Sci Res. 2021; 11(11): 161-165. DOI: https://doi.org/10.52403/ijhsr. 20211121 